\title{
HUBUNGAN $Q$-ANGLE DENGAN KESEIMBANGAN DINAMIS PADA LANJUT USIA DENGAN DIAGNOSIS OSTEOARTRITIS LUTUT DI PUSKESMAS TEGALLALANG I
}

\author{
Ni Wayan Teza Andika1, Komang Tri Adi Suparwati² ${ }^{2}$ I Putu Astrawan ${ }^{3}$, \\ I.A Ratih Wulansari Manuaba ${ }^{4}$ \\ Program Studi Fisioterapi, Fakultas Ilmu-Ilmu Kesehatan, Universitas Bali Internasional \\ tesaandika20@gmail.com, komangtriadisuparwati@iikmpbali.ac.id
}

\begin{abstract}
Osteoarthritis of the knee is a degenerative process that occurs in the elderly aged 60 years and over where the main complaints are knee pain, stiffness, limitation of joint motion, decreased flexibility and muscle strength, causing knee alignment abnormalities. The occurrence of alignment abnormalities causes a higher distribution of pressure in the joint so that it will result in instability of the patella and weakness of the quadriceps femoris muscle which results in a decrease in the ability to maintain dynamic balance. This study aims to determine the relationship between $Q$-angle and dynamic balance in the elderly with a diagnosis of knee osteoarthritis at the Tegallalang I Health Center. This sampling technique used a cross-sectional study method conducted from March 15 to April 9, 2021 with the elderly population diagnosed knee osteoarthritis that has met the inclusion criteria and exclusion criteria. Respondents were selected using a non-probability sampling technique in the form of purposive sampling, based on the sample size formula, 38 respondents were obtained. Measurement of $Q$-angle using a goniometer and dynamic balance using the time up and go test. The results showed an analysis of the relationship between $Q$-angle and dynamic balance in the elderly with a diagnosis of knee osteoarthritis with the Pearson test with $p$ results of 0.003 ( $p<0.05)$ with a correlation coefficient of 0.476 ( $r>0.05)$ which indicates a relationship the strong one. There is a relationship between $Q$-angle and dynamic balance in the elderly with a diagnosis of knee osteoarthritis.
\end{abstract}

Keywords $\quad$ : Dynamic Balance, Elderly, Knee Osteoarthritis, Q-Angle

\begin{abstract}
ABSTRAK
Osteoartritis lutut merupakan proses degeneratif yang terjadi pada lanjut usia 60 tahun ke atas yang dimana keluhan utama adalah nyeri lutut, kekakuan, keterbatasan gerak sendi, penurunan fleksibilitas dan kekuatan otot, sehingga menyebabkan abnormalitas alignmen lutut. Terjadinya abnormalitas alignmen menyebabkan distribusi tekanan yang lebih tinggi pada sendi sehingga akan mengakibatkan ketidakstabilan pada patella dan kelemahan pada otot quadriceps femoris yang mengakibatkan terjadi penurunan kemampuan mempertahankan keseimbangan dinamis. Penelitian ini bertujuan untuk mengetahui hubungan antara $Q$-angle dengan keseimbangan dinamis pada lanjut usia dengan diagnosis osteoartritis lutut di Puskesmas Tegallalang I. Tehnik pengambilan sampel ini menggunakan metode studi potong lintang yang dilakukan pada 15 Maret sampai 9 April 2021 dengan populasi lanjut usia yang di diagnosis osteoartritis lutut yang telah memenuhi kriteria inklusi dan kriteria eksklusi. Responden dipilih dengan menggunakan teknik non probability sampling dengan bentuk purposive sampling, berdasarkan rumus besar sampel didapatkan 38 responden. Pengukuran $Q$-angle dengan menggunakan goniometer dan keseimbangan dinamis menggunakan time up and go test. Hasil penelitian menunjukan analisis hubungan antara $Q$-angle dengan keseimbangan dinamis pada lanjut usia dengan diagnosis osteoartritis lutut dengan uji pearson dengan hasil $p$ sebesar 0,003 $(\mathrm{p}<0,05)$ dengan nilai koefisien korelasi sebesar $0,476(r>0,05)$ yang menunjukkan hubungan yang kuat. Terdapat hubungan antara $Q$-angle dengan keseimbangan dinamis pada lanjut usia dengan diagnosis osteoartritis lutut.
\end{abstract}

Kata Kunci : Keseimbangan Dinamis, Lanjut Usia, Osteoartritis Lutut, Q-Angle 


\section{PENDAHULUAN}

Kesehatan merupakan faktor penting bagi kehidupan manusia, karena dengan tubuh sehat secara jasmani dan rohani manusia dapat hidup dan melakukan aktivitas sehari-hari. Keberhasilan pembangunan di berbagai bidang, terutama bidang kesehatan menyebabkan terjadinya peningkatan usia harapan hidup penduduk di dunia termasuk Indonesia. Indonesia mengalami peningkatan jumlah penduduk lanjut usia dari 18 juta jiwa $(7,56 \%)$ pada tahun 2010, menjadi 25,9 juta jiwa $(9,7 \%)$ pada tahun 2019, dan diperkirakan akan terus meningkat dimana tahun 2035 menjadi 48,2 juta jiwa $(15,77 \%)$ (Kemenkes RI, 2019).

Seseorang dikatakan lanjut usia (lansia) adalah seseorang yang mencapai usia 60 tahun ke atas. Lanjut usia (lansia) bukanlah suatu penyakit, tetapi merupakan proses yang berangsur-angsur mengakibatkan menurunnya daya tahan tubuh dalam menghadapi rangsangan dari dalam dan luar tubuh. Perubahan yang menonjol pada lanjut usia adalah perubahan pada sistem muskuloskeletal. Salah satunya adalah terjadi proses degeneratif pada sendi sehingga terjadinya osteoartritis (Seruni, 2015).

Prevalensi osteoartritis di dunia termasuk dalam kategori tinggi sebesar $2,3 \%$ hingga 11,3\%, diperkirakan prevalensi osteoartritis ini akan meningkat dua kali lipat pada tahun 2020 seiring dengan pertambahan usia. Menurut The Framingham Osteoarthritis Study gambaran radiologi osteoartritis lutut yang berat yaitu, grade III dan IV berdasarkan kriteria Kellgreen-Lawrence akan makin meningkat dengan bertambahnya umur, yaitu $11,5 \%$ pada usia kurang dari 70 tahun, $17,8 \%$ pada usia $70-79$ tahun dan $19,4 \%$ pada usia lebih dari 80 tahun (Abdurrachman, 2019).

Lokasi osteoartritis yang sering ditemukan pada lanjut usia (lansia), yaitu osteoartritis pada lutut. Keluhan utama yang sering dirasakan lanjut usia (lansia) yang mengalami osteoartritis lutut adalah nyeri pada bagian lutut, kekakuan yang menyebabkan keterbatasan gerak sendi, penurunan fleksibilitas, penurunan kekuatan otot, hingga menyebabkan abnormalitas alignmen pada lutut. Abnormalitas alignmen lutut terjadi oleh karena adanya perubahan $Q$-angle dari posisi normal dan menimbulkan abnormalitas fungsi dari salah satu stabilitas yang di hasilkan Q-angle (Ekim, 2017).

$Q$-angle adalah sudut yang terletak antara garis yang menggambarkan tarikan aksial tendon otot quadriceps femoris dan garis yang membagi dua ligamen patella (Adhitya, 2017). Peningkatan sudut $Q$ angle lebih dari $15^{\circ}$ pada laki-laki dan lebih dari $20^{\circ}$ pada wanita dianggap sebagai indikasi abnormalitas alignmen yang dapat menimbulkan abnormalitas fungsi lutut (Prakash, 2017). Peningkatan sudut $Q$ angle akan memberikan distribusi tekanan yang tidak sama dan tekanan puncak yang lebih tinggi pada salah satu sendi. Jika tekanan terjadi terus menerus akan menimbulkan kelemahan yang akan memicu perubahan pada bentuk lutut, memicu terjadinya gangguan keseimbangan (Juriansari, 2020).

Keseimbangan adalah kemampuan untuk mempertahankan pusat gravitasi pada bidang tumpu terutama ketika saat posisi tegak maupun berjalan. Keseimbangan dicapai dan dikelola oleh kontrol sensorimotor yang kompleks mencakup input pada sistem sensorik dari visual, proprioseptif, vestibular, dan output motorik ke otot mata dan tubuh. Apabila terjadinya penurunan kemampuan pada sistem sensorik dan sistem muskuloskeletal dapat menyebabkan gangguan keseimbangan pada lanjut usia (lansia) (Irfan, 2016). Keseimbangan terbagi atas dua kelompok, yaitu keseimbangan statis dan keseimbangan dinamis. Keseimbangan statis adalah kemampuan yang diperlukan seseorang untuk mempertahankan tubuh dalam posisi diam. Sedangkan keseimbangan dinamis adalah kemampuan 
tubuh untuk menjaga keseimbangan saat melakukan gerakan atau aktivitas (Irfan, 2016).

Menurunnya keseimbangan pada lanjut usia (lansia) juga disebabkan karena adanya peningkatan sudut $Q$-angle karena peningkatan dari sudut $Q$-angle yang akan mengganggu gerakan pada lutut (Prakash, 2017). Terjadinya peningkatan dari sudut $Q$-angle pada osteoartritis lutut, berisiko terjadinya penurunan kemampuan fungsional lutut dan jaringan sekitarnya. Akibatnya akan terjadi kelemahan otot sehingga terjadinya penurunan kekuatan dan kontraksi otot, elastisitas dan fleksibilitas otot, serta kecepatan dan waktu reaksi sehingga dapat menyebabkan gangguan keseimbangan dinamis pada lanjut usia. Penelitian ini dilaksanakan untuk mengetahui hubungan $Q$-angle dengan keseimbangan dinamis pada lanjut usia dengan diagnosis osteoartritis lutut di Puskesmas Tegallalang I.

\section{METODE}

Penelitian ini merupakan penelitian yang menggunakan metode studi potong lintang dengan teknik pengambilan purposive sampling. Populasi target dalam penelitian ini adalah lanjut usia (lansia) dengan diagnosis osteoartritis lutut di Puskesmas Tegallalang I. Populasi terjangkau dalam penelitian ini adalah lanjut usia (lansia) dengan usia 60-90 tahun yang telah diagnosis osteoartritis lutut di Puskesmas Tegallalang I, Kecamatan Tegallalang, Kabupaten Gianyar, Provinsi Bali yang dimana penelitian ini dilakukan pada pada 15 Maret - 9 April 2021 yang telah memenuhi kriteria inklusi dan eksklusi.

Sesuai dengan kriteria inklusi dan eksklusi, didapatkan sampel berjumlah 38 responden. Alat ukur yang digunakan untuk menilai keseimbangan dinamis adalah timed up and go test yang memiliki nilai interrater reliability $r=0,99$ intrarater reliability $r=0,99$ (Podsiadlo and Richardson, 1991), sedangkan alat ukur untuk menilai Q-angle adalah goniometer yang dimana $Q$-angle normal pada laki-laki berkisar $10^{\circ}-14^{\circ}$ dan pada perempuan dari $14^{\circ}-17^{\circ}$, dan apabila sudut lebih dari $15^{\circ}$ pada laki-laki dan lebih dari $20^{\circ}$ pada wanita dikatakan secara klinis merupakan tidak normal (Abdel, 2014).

\section{HASIL}

Responden dalam penelitian ini adalah lanjut usia dengan diagnosis osteoartritis lutut di Puskesmas Tegallalang I, dengan teknik pengambilan sampel non probability sampling dengan bentuk purposive sampling yang telah memenuhi kriteria inklusi dan ekslusi. Berdasarkan rumus besar sampel yang digunakan maka responden dalam penelitian ini berjumlah 38 orang. Adapun karakteristik responden berdasarkan usia, jenis kelamin, $Q$-angle dan keseimbangan dinamis.

Tabel 1. Karakteristik Responden

\begin{tabular}{ccc}
\hline Karakteristik & $\begin{array}{c}\text { Frekuensi } \\
(\mathbf{f})\end{array}$ & $\begin{array}{c}\text { Persentase } \\
(\mathbf{\%})\end{array}$ \\
\hline Kelompok Usia & & \\
$60-70$ tahun & 27 & $71,1 \%$ \\
$71-90$ tahun & 11 & $28,9 \%$ \\
Jenis Kelamin & & \\
Laki-laki & 4 & $10,5 \%$ \\
Perempuan & 34 & $89,5 \%$ \\
Sudut $Q$-angle & & \\
Normal & 3 & $7,9 \%$ \\
Tidak normal & 35 & $92,1 \%$ \\
Keseimbangan & & \\
Dinamis & & $31,6 \%$ \\
Risiko jatuh ringan & 12 & $68,4 \%$ \\
Risiko jatuh sedang & 26 & $\mathbf{1 0 0 \%}$ \\
\hline Jumlah & $\mathbf{3 8}$ &
\end{tabular}

Pada tabel 1, menunjukkan bahwa responden terbanyak pada usia 60-70 tahun yaitu berjumlah 27 responden $(71,1 \%)$ dibandingkan usia 71-90 tahun berjumlah 11 responden $(28,9 \%)$, responden berjenis kelamin perempuan lebih banyak yaitu berjumlah 34 responden $(89,5 \%)$ dibandingkan dengan laki-laki berjumlah 4 responden $(10,5 \%)$, responden dengan $Q$ angle tidak normal lebih banyak yaitu 
berjumlah 35 responden $(92,1 \%)$ dibandingkan dengan $Q$-angle normal berjumlah 3 responden $(7,9 \%)$, responden terbanyak memiliki keseimbangan dinamis risiko jatuh sedang yaitu berjumlah 26 responden $(68,4 \%)$ dibandingkan dengan risiko jatuh ringan berjumlah 12 responden $(31,6 \%)$.

Tabel 2. Silang Q-angle dengan Keseimbangan Dinamis

\begin{tabular}{|c|c|c|c|c|c|c|}
\hline \multirow{3}{*}{$Q$-angle } & \multicolumn{4}{|c|}{ Keseimbangan Dinamis } & \multirow{2}{*}{\multicolumn{2}{|c|}{ Total }} \\
\hline & \multicolumn{2}{|c|}{$\begin{array}{c}\text { Risiko } \\
\text { Jatuh } \\
\text { Ringan }\end{array}$} & \multicolumn{2}{|c|}{$\begin{array}{c}\text { Risiko } \\
\text { Jatuh } \\
\text { Sedang }\end{array}$} & & \\
\hline & $\mathbf{F}$ & $\%$ & $\mathbf{F}$ & $\%$ & $\mathbf{N}$ & $\%$ \\
\hline Normal & 3 & $7,9 \%$ & 0 & $0,0 \%$ & 3 & $7,9 \%$ \\
\hline $\begin{array}{c}\text { Tidak } \\
\text { normal }\end{array}$ & 9 & $23,7 \%$ & 26 & $68,4 \%$ & 35 & $92,1 \%$ \\
\hline Total & 12 & $31,6 \%$ & 26 & $68,4 \%$ & 38 & $100 \%$ \\
\hline
\end{tabular}

Pada tabel 2, menunjukkan bahwa dari 38 responden terdapat responden dengan $Q$-angle normal pada keseimbangan dinamis kategori risiko jatuh ringan berjumlah 3 responden $(7,9 \%)$ dan responden dengan $Q$-angle normal pada keseimbangan dinamis kategori risiko jatuh sedang berjumlah 0 responden $(0,0 \%)$. Sedangkan responden dengan $Q$-angle tidak normal pada keseimbangan dinamis kategori risiko jatuh ringan berjumalah 9 responden $(23,7 \%)$ dan responden dengan $Q$-angle tidak normal pada keseimbangan dinamis kategori risiko jatuh sedang berjumlah 26 responden $(68,4 \%)$.

\section{Uji Hipotesis}

Bertujuan untuk membuktikan bahwa terdapat hubungan $Q$-angle dengan keseimbangan dinamis pada lanjut usia dengan diagnosis osteoatritis lutut di Puskesmas Tegallalang I.

\section{Uji Asumsi} tabel 3

Hasil uji linearitas dapat dilihat pada

Pada tabel 3, menunjukkan bahwa data hasil penelitian setelah dilakukan uji linearitas didapatkan hasil nilai $\mathrm{p}$ sebesar $0,005(\mathrm{p}<0,05)$ dan nilai deviasi linearitas p sebesar 0,932 ( $>>0,05)$, berdasarkan hasil tersebut menunjukkan data bersifat linear.

Tabel 3. Hasil Uji Linearitas

\begin{tabular}{|c|c|c|}
\hline Uji Linearitas & Nilai & Keterangan \\
\hline Nilai $p$ & 0,005 & Sig. $\mathrm{p}<0,05$ \\
\hline $\begin{array}{l}\text { Deviasi } \\
\text { Linearitas }\end{array}$ & 0,932 & Sig. $p>0,05$ \\
\hline
\end{tabular}

Hasil uji normalitas tabel hasil uji normalitas dapat dilihat pada tabel berikut :

\begin{tabular}{ccc}
\hline Tabel 4. Hasil Uji Normalitas & \\
\hline Variabel & $\mathbf{p}$ & Keterangan \\
\hline$Q$-angle & 0,223 & Normal \\
Keseimbangan Dinamis & 0,186 & Normal \\
\hline
\end{tabular}

Pada tabel 4, menunjukkan bahwa data hasil penelitian setelah dilakukan uji normalitas menggunakan uji Shapiro-Wilk menunjukkan hasil bahwa, pada variabel $Q$ angle didapatkan hasil nilai p sebesar 0,223 ( $p>0,05$ ) dan pada variabel keseimbangan dinamis didapatkan nilai $\mathrm{p}$ sebesar 0,186 ( $\mathrm{p}$ $>0,05)$. Berdasarkan hasil tersebut menunjukkan data berdistribusi normal.

\section{Uji Korelasi Pearson}

Tabel 5. Hasil Uji Korelasi Pearson

\begin{tabular}{lcc}
\hline \multicolumn{1}{c}{ Uji Korelasi } & Nilai & Keterangan \\
\hline Nilai $\mathrm{p}$ & 0,003 & $\begin{array}{c}\text { Signifikan } \mathrm{p} \\
<0,05\end{array}$ \\
$\begin{array}{l}\text { Nilai Koefisien } \\
\text { Korelasi }\end{array}$ & 0,476 & Korelasi kuat \\
Arah Korelasi & $(+)$ & Positif \\
\hline
\end{tabular}

Pada tabel 5, menunjukkan bahwa hasil penelitian setelah dilakukan uji analisis korelasi pearson untuk mencari hubungan $Q$-angle dengan keseimbangan dinamis pada lanjut usia dengan diagnosis osteoatritis lutut di Puskesmas Tegallalang I, yaitu menunjukkan hasil nilai $\mathrm{p}=0,003$ yang berarti memiliki nilai signifikan $p$ $<0,05$ hal tersebut menunjukkan bahwa $Q$ angle memiliki hubungan atau korelasi dengan keseimbangan dinamis pada lanjut 
usia dengan diagnosis osteoatritis lutut. Serta didapatkan hasil nilai koefisien korelasi 0,476 hal tersebut menunjukkan bahwa memiliki korelasi yang kuat dan memiliki arah yang positif.

\section{PEMBAHASAN}

Hasil uji korelasi pearson menunjukkan terdapat hubungan yang signifikan antara $Q$-angle dengan keseimbangan dinamis pada lanjut usia dengan diagnosis osteoartritis lutut, dengan hasil nilai $\mathrm{p}=0,003$ dimana nilai signifikansi yaitu $p<0,05$. Selain itu didapatkan juga nilai koefisien korelasi (r) sebesar 0,476 artinya penelitian ini memiliki korelasi kuat antara $Q$-angle dengan keseimbangan dinamis pada lanjut usia dengan diagnosis osteoatritis lutut dan hasil penelitian ini memiliki arah yang positif. Hal ini sesuai dengan hasil penelitian yang dilakukan oleh Kulli (2019), yang menyatakan bahwa terdapat hubungan $Q$-angle dengan keseimbangan dinamis yang signifikan dengan nilai $\mathrm{p}=0,027$.

Pada lanjut usia akan terjadi proses degeneratif pada sendi lutut, dimana terjadinya penurunan cairan kartilago pada sendi yang menyebabkan terjadinya osteoartrtitis lutut (Ekim, 2017). Osteoartritis lutut ditandai dengan adanya nyeri pada lutut, kekakuan yang mengakibatkan keterbatasan gerak sendi sehingga menyebabkan terjadinya kelemahan otot dan peningkatan sudut $Q$ angle (Juriansari, 2020).

Peningkatan sudut $Q$-angle dari batas normal menyebabkan terjadinya abnormalitas alignmen pada lutut (Juriansari, 2020). Sejalan dengan penelitian yang dilakukan oleh Bozbas (2018) tentang hubungan abnormalitas alignmen ektremitas bawah terhadap risiko jatuh pada lanjut usia mendapatkan hasil yang signifikan yaitu nilai $\mathrm{p}<0,05$. Hasil tersebut menunjukkan bahwa terjadinya abnormalitas alignmen pada ekstremitas bawah akan menyebabkan terjadinya peningkatan risiko jatuh pada lanjut usia.

Menurut Kumar (2018) dan Juriansari (2020), menyatakan bahwa abnormalitas alignmen lutut mengakibatkan tekanan yang lebih tinggi pada salah satu sendi sehingga menyebabkan ketidakstabilan pada posisi patella, dimana dapat menggeser patella ke lateral ketika lutut dalam posisi fleksi dengan sudut $20^{\circ}$ hingga $60^{\circ}$. Hal tersebut yang dapat menyebabkan terjadi tekanan kontak pada fatellofemoral lateral. Tekanan pada patella secara terurmenerus mengakibatkan ketidakseimbangan hingga kelemahan otot vastus medialis dan vastus lateralis dari quadriceps femoris yang merupakan otot yang bekerja secara aktif dalam mengontrol posisi patella (Tahid, 2006).

Kelemahan otot terutama pada ektremitas bawah dapat mengakibatkan ketidakseimbangan kekuatan otot yang bekerja saat berjalan sehingga dapat mempengaruhi kemampuan tubuh dalam menjaga keseimbangan dinamis (Utomo, 2010). Kekuatan otot merupakan faktor penting dalam menjaga keseimbangan dinamis oleh karena keseimbangan membutuhkan interaksi yang kompleks dari sistem sensorimotor yang mencakup visual, proprioseptif, vestibular dan muskuloskeletal (Irfan, 2016).

Pada sistem muskuloskeletal membutuhkan kekuatan otot yang baik untuk menunjang keseimbangan dinamis pada lanjut usia (Dewi, 2020). Lanjut usia yang memiliki $Q$-angle tidak normal terjadinya penurunan kekuatan kontraksi isokinetik pada otot quadriceps femoris sehingga mengakibatkan penurunan pada keseimbangan dinamis (Taşmektepligil, 2018). Berdasarkan hasil penelitian Juliastuti (2020) menyatakan bahwa $Q$ angle merupakan indikator yang sangat penting untuk menentukan fungsi biomekanik pada ekstremitas bawah karena pengukuran ini mencerminkan efek mekanisme otot quadriceps femoris pada lutut. Menurut hasil dari penelitian Prasetio dan Djauhari (2015), menyatakan bahwa 
otot quadriceps femoris mempengaruhi keseimbangan postural sebesar 59,6\%. Sejalan dengan penelitian Noviyanti (2014), yang menunjukkan bahwa adanya korelasi antara kekuatan otot quadriceps femoris dengan risiko jatuh. Semakin baik kekuatan otot pada lanjut usia maka risiko jatuh semakin rendah dan begitu sebaliknya semakin rendah kekuatan otot semakin tinggi risiko jatuh. Hal ini disebabkan karena gerak dengan pola normal berasal dari adanya perencanaan gerak yang diimplementasikan dalam bentuk aktivasi otot dengan kekuatan dan kecepatan yang sesuai. Kemampuan otot untuk melakukan reaksi tegak dan stabil merupakan bentuk dari aktivitas otot untuk menjaga keseimbangan dinamis (Asti, 2020).

Penurunan kekuatan otot berhubungan dengan penurunan masukan reseptor dari proprioseptif yang merupakan bagian yang terpenting dari keseimbangan. Propioseptif adalah kemampuan tubuh untuk merasakan posisi bagian sendi atau tubuh dalam gerak. Komponen propioseptif ini berperan dalam menjaga keseimbangan dinamis yang memiliki hubungan dengan traktus spinoserebralis posterior dan anterior. Kedua traktus ini yang membawa informasi propioseptif dari ekstremitas bawah. Sinyal-sinyal yang dijalarkan dalam traktus spinoserebralis posterior berasal dari kumparan otot dan sebagian kecil berasal dari reseptor somatik di seluruh tubuh, seperti organ tendon golgi, reseptor taktil yang besar pada kulit, dan reseptor-reseptor sendi (Nugraha et al., 2016). Semua sinyal ini memberitahu serebelum tentang bagaimana keadaan terkait kontraksi otot, derajat ketegangan tendon otot, posisi dan kecepatan gerakan bagian tubuh, dan kekuatan kerja pada permukaan tubuh (Apriani et al., 2015).

Pada lanjut usia terjadi kelemahan otot akan mengakibatkan penurunan kemampuan input proprioseptif. Kombinasi gangguan tersebut dapat mengakibatkan keterlambatan gerak dan kaki tidak menapak dengan kuat dan cendrung tampak goyah sehingga meningkatkan risiko jatuh pada lanjut usia (Widarti dan Triyono, 2018).

\section{KESIMPULAN}

Berdasarkan hasil penelitian dan pembahasan, maka dapat disimpulkan bahwa terdapat hubungan yang siginifikan antara $Q$-angle dengan keseimbangan dinamis pada lanjut usia dengan diagnosis osteoartritis lutut di Puskesmas Tegallalang I dengan hasil nilai $\mathrm{p}=0,003$ dengan nilai signifikansi yaitu $\mathrm{p}<0,05$ dan memiliki nilai koefisien korelasi (r) sebesar 0,476 menunjukkan bahwa hasil penelitian ini memiliki korelasi yang kuat dan memiliki arah yang positif.

\section{UCAPAN TERIMA KASIH}

Ucapan terima kasih disampaikan kepada Bapak Kepala Puskesmas Tegallalang I dan seluruh lanjut usia yang sudah bersedia membantu dalam proses penelitian ini, para pembimbing, teman-teman Fisioterapi Fakultas Ilmu-Ilmu Kesehatan Universitas Bali Internasional yang turut membantu dan memberikan banyak masukan dalam menyelesaian penelitian ini serta kepada keluarga tercinta yang telah mengasuh, membesarkan penulis serta mendidik penulis dan mengajarkan penulis dengan penuh kasih sayang, ikhlas, serta penuh kesabaran. Dan telah mengajarkan kepada penulis bahwa lebih baik membantu daripada memberi dan jika ingin sesuatu harus memiliki niat yang kuat di tegaskan dengan usaha dan doa, serta memberikan dasar-dasar berpikir logika, serta keadaan apapun selalu bersyukur dan berdoa kepada Ida Sang Hyang Widhi Wasa/Tuhan Yang Maha Esa.

\section{DAFTAR PUSTAKA}

Abdel-aziem. 2014. Effect of Body Position on Measurement of $Q$ Angle in Trained Individuals with and without Patellofemoral Pain. International Journal of Therapies and Rehabilitation Research [E-ISSN: 2278-0343] http://www.scopemed.org/?jid=12 IJTRR 2014, 3: 3 I doi: 10.5455/ijtrr.00000031. 
Abdurrachman, M. (2019). Insights into eruption dynamics from the 2014 pyroclastic deposits of Kelut volcano, Java, Indonesia, and implications for future hazards. Journal of Volcanology and Geothermal Research, 382, 6-23.

Adhitya, I.P. 2017. Penambahan Kinesiology Tape Pada Pelatihan Closed Kinetic Chain $(C K C)$ Dan Stretching Lebih Baik Dalam Menurunkan Excessive Q-Angle Pada Wanita. Sport and Fitness Journal. ISSN: 2302-688X Volume 5, No.3, September 2017: 93.100.

Apriani, Tianing, Adiartha Griadhi. 2015. Pemberian Pelatihan Balance Strategy Exercise Lebih Baik Daripada Pelatihan Core Stability Exercise Dalam Meningkatkan Keseimbangan Dinamis Pada Lansia Di Banjar Bumi Shanti, Desa Dauh Puri Kelod, Kecamatan Denpasar Barat

Asti, N. P. I. P., Yanti, N. L. P. E., \& Astuti, I. W. (2020). Hubungan Kekuatan Otot dan Tingkat Stres dengan Risiko Jatuh pada Lansia. Jurnal Ners Widya Husada, 4(2), 41-46.

Bozbaş, G. T., \& Gürer, G. (2018). Does the lower extremity alignment affect the risk of falling?. Turkish journal of physical medicine and rehabilitation, 64(2), 140.

Dewi K. 2020. Hubungan Keseimbangan Statis Dan Dinamis Terhadap Kemandirian Dalam Melakukan Aktivitas Sehari-Hari Pada Lansia di PWRI Kota Denpasar. (Skripsi). Denpasar: Universitas Bali Internasional

Ekim, A. A., Hamarat, H. \& Musmul, A., 2017. Relationship Between Q-Angle and Articular Cartilage in Female Patients With Symptomatic Knee Osteoarthritis: Ultrasonographic and Radiologic Evaluation. Arch Rheumatologi, 32(4), pp. 347-352.

Irfan. 2016. Keseimbangan pada Manusia. [Online] https://ifi.or.id/artikel02.html. Diakses 25 Desember 2020

Juliastuti dan Putri Edrivania. 2020. Hubungan Quadriceps Angle Terhadap Fungsional Lutut Pada Kasus Knee Osteoarthritis di Panti Lanjut Usia Harapan Kita Palembang. Jurnal Masker Medika eISSN: 2654-8658 p-ISSN: 2301-8631

Juriansari D., Naufal A.F \& Widodo A. 2020. Hubungan Q-Angle Terhadap Keluhan
Osteoarthritis Pada Lansia. Fisiomu.2020

Vol 1(2): $42-48$ DOI: 10.23917/j.fisiomu.v\%vi\%i.10525.

Kemenkes RI. 2019. Indonesia Memasuki Aging Population. [Online] https://www.kemkes.go.id/article/view/1 9070500004/indonesia-masuki-periodeaging-population.html. Diakses 10 Desember 2020

Kulli Denızoglu, H., Yeldan, I., \& Yildirim, N. U. (2019). Influence of quadriceps angle on static and dynamic balance in young adults. Journal of back and musculoskeletal rehabilitation, 32(6), 857-862.

Kumar, C., Thapa, S. S. \& Lamichhane, A. P., 2018. The Relationship of Quadriceps Angle and Anterior Knee Pain. Journal of Clinical and Diagnostic Research, XII(DOI:10.7860/JCDR/2018/34697.124 $11)$, pp. 13-16.

Noviyanti, S., Santoso, T. B., Fis, S., Widodo, A., \& Fis, S. (2014). Hubungan Kekuatan Otot Quadriceps Femoris dengan Risiko Jatuh pada Lansia (Doctoral dissertation, Universitas Muhammadiyah Surakarta).

Nugraha, M. H. S., Wahyuni, N., \& Muliarta, I. M. (2016). Pelatihan 12 Balance Exercise Lebih Meningkatkan Keseimbangan Dinamis Daripada Balance Strategy Exercise Pada Lansia Di Banjar Bumi Shanti, Desa Dauh Puri Kelod, Kecamatan Denpasar Barat. Majalah Ilmiah Fisioterapi Indonesia, 1(1)

Podsiadlo, D., Richardson, S., "The Time Up and Go Test : A Test of Basic Functional Mobility for Frail Elderly Persons", Journal American Geriatrics Society. Vol.39, 1991.

Prakash, V., Sahay, P. \& Satapathy, A., 2017. Correlation between Body Mass Index, Waist Hip Ratio \& Quadriceps Angle in Subjects with Primary Osteoarthritic Knee. International Journal of Health Sciences and Research, VII(6), pp. 197205.

Prasetio, A. D., \& Djauhari, T. (2015). Analisis Kekuatan M. Quadrisep Femoris Terhadap Resiko Gangguan Keseimbangan Postural. Saintika Medika: Jurnal Ilmu Kesehatan dan Kedokteran Keluarga, 11(1), 8-13. 
Saç, A., \& Taşmektepligil, M. Y. (2018). Correlation between the $Q$ angle and the isokinetic knee strength and muscle activity. Turkish journal of physical medicine and rehabilitation, 64(4), 308.

Seruni Beata Dinda. 2015. Perbedaan Skor Pasien Osteoartritis Antara Sebelum Dan Sesudah Terapi IR Dan Tens Berdasarkan LI (Lequesne Index) Dan WOMAC (Western Ontario And Mcmaster Universities Osteoarthritis Index). (Skripsi). Surakarta: Universitas Sebelas Maret.

Tahid, A. (2006). Hubungan antara peningkatan sudut $\mathrm{Q}$ dan perubahan pola ajakan otot
Vastus Medialis Oblique dan Vastus Lateralis dengan derajat nyeri dan derajat kerusakan sendi pada penderita Osteoartritis Lutut.

Utomo, Budi. 2010. Hubungan antara Kekuatan Otot dan Daya Tahan Otot Anggota Gerak Bawah dengan Kemampuan Fungsional Lanjut Usia. Tesis. Surakarta: Program Pasca Sarjana Universitas Sebelas Maret Surakarta.

Widarti, R., \& Triyono, E. 2018. Pemberian Ankle Strategy Exercise Pada Lansia Terhadap Keseimbangan Dinamis. Gaster, 16(1), 83-93. 